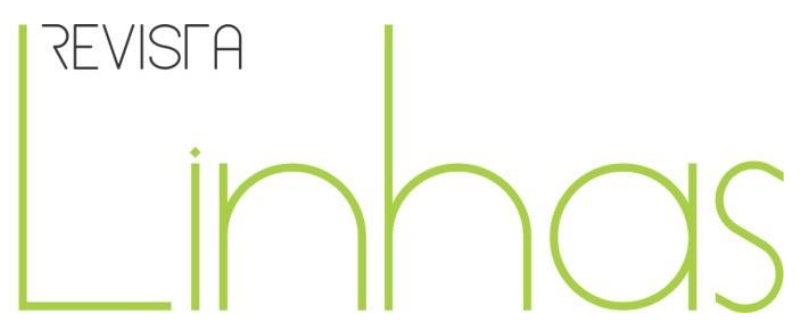

\title{
O trabalhador docente na escola pública: Novos elementos de subsunção ao capital
}

\section{Resumo}

Neste artigo, problematizamos o papel do Estado no capitalismo contemporâneo em relação ao aprofundamento da crise mundial do capitalismo e a subsequente necessidade de soluções, via reformas impopulares, para se contrapor à queda tendencial da taxa de lucro. Para tanto, buscamos apoio nos escritos de Marx, Engels, Lenin, Gramsci e outros autores do campo marxista, e retomamos as seguintes categorias e conceitos: trabalho, trabalho produtivo e improdutivo, lei da queda tendencial da taxa de lucro, e a crise do capital. Como expressão desses elementos de subsunção ao capital, apresentamos o caso da Rede Municipal de Educação de Florianópolis, destacando processos de terceirização, subvenções sociais, e as novas formas de contratação de trabalhadores docentes.

Palavras-chave: Crise do capital. Trabalhador docente. Rede Municipal de Educação de Florianópolis.
Juliana Matias Faust

Universidade do Estado de Santa

Catarina - UDESC - Florianópolis/SC - Brasil

jmffaust@gmail.com

Mariano Moura Melgarejo

Universidade do Estado de Santa

Catarina - UDESC - Florianópolis/SC - Brasil

marianom@gmail.com

\section{Mariléia Maria da Silva}

Universidade do Estado de Santa

Catarina - UDESC - Florianópolis/SC - Brasil

marileiamaria@hotmail.com

\section{Para citar este artigo:}

FAUST, Juliana Matias; MELGAREJO, Mariano Moura; DA SILVA, Mariléia Maria. O trabalhador docente na escola pública: Novos elementos de subsunção ao capital. Revista Linhas. Florianópolis, v. 21, n. 46, p. 145172, maio/ago. 2020. 


\title{
The teaching worker in public school: New elements of subsumption to the capital
}

\begin{abstract}
In this article we problematize the role of the State in the contemporary capitalism in relation to the deepening of the global crisis of capitalism and the subsequent need for solutions, via unpopular reforms, to counteract to the tendency of the rate of profit to fall. For this purpose, we seek support in the writings by Marx, Engels, Lenin, Gramsci and other authors of the Marxist area, and we resume the following categories and concepts: labour, productive and unproductive labour, law of tendency of the rate of profit to fall, and the capital crisis. As expression of these elements of subsumption to the capital, we present the case of the Florianópolis municipal school system, highlighting outsourcing processes, social subventions, and the new forms of hiring of teaching workers.
\end{abstract}

Keywords: Capital crisis. Teaching worker. Florianópolis municipal school system. 
Karl Marx (1818-1883), em uma perspectiva materialista e histórica, realizou uma profunda análise do movimento e das determinações do modo de produção capitalista. Formulou categorias explicativas do funcionamento da sociedade que são ferramentas fundamentais para quem deseja apreender e explicar os fenômenos sociais atuais, e permanecerão enquanto esse modo de produção social não estiver superado. A partir desse pressuposto, abordamos de forma exploratória as relações entre capital-trabalho no padrão de acumulação flexível do capitalismo, com o objetivo de compreender o trabalhador docente na educação básica pública brasileira no contexto de crise e movimentos de contratendência do capital. Problematizamos o papel do Estado no capitalismo contemporâneo e a relação com o aprofundamento da crise mundial do capitalismo e a subsequente necessidade de soluções, via reformas impopulares, para se contrapor à queda tendencial da taxa de lucro. Para tanto, buscamos apoio nos escritos de Marx, Engels, Lenin, Gramsci e outros autores do campo marxista, e retomamos as seguintes categorias e conceitos: trabalho, trabalho produtivo e improdutivo, lei da queda tendencial da taxa média de lucro, e a crise do capital. Como expressão desses elementos de subsunção ao capital, apresentamos o caso da Rede Municipal de Educação de Florianópolis, destacando os processos de terceirização e as novas formas de contratação de trabalhadores docentes.

O presente artigo está dividido em dois tópicos, além desta introdução e considerações finais, a saber: no primeiro, apresentamos de forma sintética a intrínseca relação entre o Estado e as necessidades do capital, apontando alguns elementos característicos dessa relação, suas formas de expressão no capitalismo contemporâneo e suas crises; no segundo, tomando como estudo de caso a Secretaria Municipal de Educação de Florianópolis, evidenciamos a punção do fundo público via contratos derivados do empréstimo com o Banco Interamericano de Desenvolvimento (BID), contratos de terceirização da força de trabalho com empresas privadas, e o repasse à organizações da sociedade civil por meio de subvenções sociais, destacando, entre outros aspectos, o crescente processo de precarização do trabalho docente. Por fim, algumas considerações que reforçam a existência da estreita relação entre a crise do capital, a queda tendencial da taxa de lucro e o uso do fundo público. 


\section{O capital em crise e o Estado a serviço do capital}

A compreensão da dinâmica do Estado no capitalismo contemporâneo passa necessariamente pelo reconhecimento da existência de classes sociais. O papel do Estado para a efetivação da agenda privada mercantil é continuar criando as condições necessárias para a extração do mais-valor e recuperação da taxa de lucro. No primeiro capítulo da obra O Estado e a Revolução, Lenin recupera o estudo de Engels sobre o desenvolvimento histórico do Estado, presente na obra A Origem da Família, da Propriedade Privada, e do Estado, para afirmar que:

O Estado é o produto e a manifestação do antagonismo inconciliável das classes. O Estado aparece onde e na medida em que os antagonismos de classes não podem objetivamente ser conciliados. E, reciprocamente, a existência do Estado prova que as contradições de classes são inconciliáveis. (LENIN, 1986, p. 27)

$\mathrm{Na}$ relação de impossibilidade de conciliação de interesses das duas classes fundamentais no capitalismo é que se encontra o Estado. Nesses termos, o Estado é o Estado da classe economicamente dominante. Lenin retoma essa ideia, afirmando que: "Para Marx, o Estado é um órgão de dominação de classe, um órgão de submissão de uma classe por outra; é a criação de uma ‘ordem’ que legalize e consolide essa submissão, amortecendo a colisão das classes." (LENIN, 1986, p. 04). É por meio dele que a classe dominante exerce seu domínio político, ampliando os meios de oprimir e explorar a classe dominada.

Gramsci (1989), reafirmando a função básica do Estado apontada por seus antecessores, ao olhar para o mundo em seu tempo histórico, identificou a complexificação da sociedade diante da formação de grandes sindicatos, partidos, sistemas educacionais, círculos de cultura, entre outros, e enriqueceu a concepção de Marx e Engels, acrescentando outras determinações ao formular o conceito de Estado integral. Esse conceito é caracterizado pela relação dialética entre sociedade civil e sociedade política. A sociedade política corresponde ao governo jurídico, ao Estado restrito, em que o exercício do poder se dá através da dominação mediante a coerção pelos aparelhos repressivos do Estado. A sociedade civil abarca a direção política e o 
consenso, e exerce seu poder pelos aparelhos privados de hegemonia (SIMIONATTO, 2011). Ao ampliar o conceito de Estado, Gramsci admite que o Estado é atravessado pela luta de classes e desenvolve conceitos e categorias fulcrais para a formulação de táticas e estratégias para as lutas da classe trabalhadora. Os ciclos de crise econômica, que veremos a seguir, são ilustrativos para demonstrar a subordinação do Estado às necessidades da acumulação de capital.

A apreensão do trabalhador docente no movimento do capital pressupõe a compreensão da dinâmica de valorização do valor e acumulação. No desenvolvimento da produção capitalista, a quantidade de capital variável (v), referente aos investimentos em força de trabalho, tende a declinar, e o capital constante (c), que trata dos meios de produção, como máquinas e tecnologias, tende a aumentar. Marx (2008) cunha a relação entre esses diferentes capitais como composição orgânica do capital (coc), expressa pela fórmula $\operatorname{coc}=\mathrm{c} / \mathrm{v}$. O desenvolvimento das forças produtivas tem como consequência a diminuição do uso da força de trabalho pela incorporação de novos maquinários que automatizam parte do trabalho, ou seja, as mercadorias são produzidas em menos tempo, com menos uso da força de trabalho, aumentando assim a composição orgânica de capital. Como o mais-valor só pode ser expropriado da força de trabalho, que é trabalho vivo e não de máquinas, a taxa de lucro tende a diminuir. Nas palavras do autor:

[...] por meio do crescente emprego de maquinaria e de capital fixo, de modo geral mais matérias-primas e auxiliares são transformadas pelo mesmo número de trabalhadores no mesmo tempo, ou seja, com menos trabalho, em produtos. Corresponde [...] um crescente barateamento do produto. Cada produto individual, considerado em si, contém uma soma menor de trabalho do que em estágios inferiores da produção. [...] expressa, portanto, a tendência real da produção capitalista. Esta, com o progressivo decréscimo relativo do capital variável em relação ao capital constante, gera uma composição orgânica crescentemente superior do capital global, cuja consequência imediata é que a taxa de mais-valia, com grau constante e até mesmo crescente de exploração do trabalho, se expressa numa taxa geral de lucro em queda contínua. (MARX, 2008, p. 164)

O que o Marx (2008) chama aqui de lucro, é o mais-valor. Então, se há uma tendência de queda da taxa média de mais-valor, que é o pilar que sustenta o capitalismo, há também uma tendência a crises cíclicas. Na mesma direção, Mészáros (2010), ao tratar 
das crises cíclicas e da crise estrutural do capital, destaca a importância do Estado capitalista nesses momentos de ampliação do capital, evidenciando que não existe capital sem crise, ou seja, a crise cíclica faz parte do metabolismo de acumulação do capital. lasi (2017) adverte que aquilo que a princípio identificamos como crise, na verdade são os sinais da saída dela. Essa saída se dá pelo movimento de contratendências que são as formas pelas quais o capital busca recuperar o crescimento e/ou minimizar a queda da taxa de lucro. O Estado tem papel fundamental na administração desse processo.

A resposta econômica do capital às crises a partir da década de 1970-1980 é marcada pela ascensão do capital financeiro. A financeirização tem como forma de atuação a "[...] liberalização da circulação mundial de capitais, derrubando as barreiras internas ou nacionais para o livre trânsito de capitais, seja sob a forma monetária ou da mercadoria - entre as quais, a força de trabalho." (SEKI, 2017, p. 06).

\subsection{A educação pública na mira do capital}

A transformação da educação em mercadoria, no Brasil, remonta pelo menos ao período da ditadura militar, contudo, a internacionalização da oferta educacional e a penetração do capital financeiro expandiram e aprofundaram esse fenômeno (OLIVEIRA, 2009). O autor constatou que em 1990, os fundos de investimentos privados passaram a investir principalmente na educação básica.

No ensino superior, as matrículas foram largamente ampliadas desde o período militar, e mais ainda nos Governos FHC (PSDB), Lula e Dilma (PT), priorizando, no entanto, as instituições privadas: “[...] em 2015, os dados do Censo da Educação Superior, somaram 8,03 milhões de matrículas." (INEP, 2016 apud SEKI, 2017, p. 02).

Pesquisadores da área demonstram o crescimento extravagante do setor financeiro na educação, com uma variedade de transações que atuam na formação de grandes monopólios por meio de fusões de capitais e a circulação de bilhões de reais. Atualmente, as Instituições de Ensino Superior (IES) privadas concentram 75\% do total de matrículas no Brasil (SEKI, 2017).

De 2001 a 2008, o setor de ensino privado aumentou seu movimento de capitais de $\mathrm{R} \$ 10$ bilhões para $\mathrm{R} \$ 90$ bilhões (OLIVEIRA, 2009). A atuação dessas empresas não fica 
restrita à oferta de cursos presenciais e a distância - outras facetas, como materiais didáticos, consultoria, softwares, empresas de avaliação em larga escala, gestão do setor público, são mercados em atuação. O Brasil, quinto país mais populoso do mundo, com metas ainda a cumprir de expansão de oferta da educação infantil ao ensino superior, é visto como uma grande oportunidade de mercado:

De acordo com o consultor, na educação básica, esses movimentos econômicos ainda são mais recentes e em fase de desenvolvimento. ' $O$ grande objetivo dos grupos de investimento da área educacional é o aumento da rentabilidade através de ganhos de escalas, com um portfólio de professores multidisciplinares e o desenvolvimento de conteúdos online'. [...] 'Se utilizarmos como base o grupo Kroton, que possui valor de mercado de $\mathrm{R} \$ 28,19$ bilhões e cerca de 1 milhão de alunos, e considerarmos que o Brasil possui 6 milhões de alunos no ensino superior privado, poderíamos dizer que o mercado de educação superior privado no Brasil seria da ordem de $\mathrm{R} \$ 169$ bilhões, caso todo o mercado operasse no mesmo padrão de eficiência da Kroton', calcula Tarcísio Villela, consultor da Hoper Educação. (KAMARAD, 2017, documento online)

O papel do Estado para a efetivação da agenda privada mercantil foi e continua sendo decisivo, criando as condições necessárias para a extração do mais-valor, reprimindo o que se configura como ameaça ao modo de produção e buscando garantir que a ideologia da classe capitalista continue dominante. Diante da necessidade de produção de novas mercadorias e das dificuldades enfrentadas para a expansão do capital, o fundo público tornou-se um atrativo cobiçado pelo setor privado. Evidencia-se uma modificação qualitativa nas políticas sociais, que são transformadas em mercadoria, deslocando os recursos destinados a atender os direitos dos trabalhadores para socorrer os capitalistas (GRANEMANN, 2017). De acordo com a autora, o Estado disponibiliza os recursos do fundo público para programas de transferência monetarizada (pois passam pelo controle das instituições bancárias financeiras) para os usuários. Ao ingressar no sistema bancário, o fundo público serve de lastro para a criação de capital fictício. Dessa forma, o mesmo dinheiro que é usado para a política social serve para aquecer o mercado financeiro, fornecendo recursos para a compra de ações, títulos públicos, especulação, e para grandes investimentos. 
A mais recente ação da maior empresa financeirizada da educação superior, a Kroton Educacional, aponta para uma outra modalidade de assalto ao fundo público, a aquisição de empresas que dominam o mercado de livros didáticos e sistemas educacionais na educação básica (SEKI, 2018). A hipótese é de que o know-how desse conglomerado na área da educação a distância, no ensino superior, deve servir como vantagem competitiva para o domínio do ensino médio privado, uma vez que a atual reforma desse nível de ensino prevê que até $60 \%$ do currículo pode ser ofertado na modalidade a distância.

Em publicações voltadas aos empresários, encontramos indícios dessa atuação:

\begin{abstract}
O Ministério da Educação (MEC) publicou, no último mês de junho [de 2017], uma portaria que acelera e flexibiliza a implantação de cursos superiores na modalidade a distância. De acordo com o MEC, a portaria possibilita o credenciamento das IES para cursos de educação a distância (EaD) sem o credenciamento para cursos presenciais. [...] Com a mudança, e principalmente com a flexibilização adquirida, a licença do ensino a distância passa a oferecer às instituições a possibilidade de abrir novos polos EaD em todo o país", opina Villela. [...] Nos últimos anos, o governo tem incentivado o desenvolvimento do setor, diminuindo a burocracia para a abertura de novas faculdades, o que atraiu investidores de todo o mundo. (KAMARAD, 2017, documento online)
\end{abstract}

Entendemos que a compreensão dos empresários de que as "lacunas" do segmento educacional são oportunidades de negócio, evidencia movimentos de contratendência que visam aumentar a taxa de mais-valor em vários segmentos, inclusive com a venda da mercadoria 'ensino' para o Estado, explorando o trabalho excedente do professor que atua nas escolas públicas, seja mascarado pela forma jurídica de Organizações da Sociedade Civil (OSCs) ou com repasse direto de recursos públicos para a compra de vagas em instituições privadas de ensino. No âmbito da educação, as parcerias público-privadas tomam dimensão ainda maior com a crescente entrega da gestão de unidades escolares para as OSCS, que estabelecem vínculos com a gestão pública de municípios, estados e governo federal, abocanhando parte do fundo público na gestão de políticas sociais, das quais trataremos aqui, em especial a gestão de creches e pré-escolas. 


\subsection{O trabalhador docente nas relações atuais entre capital-trabalho e educação}

No contexto das reformas necessárias ao capital, no Brasil, a Reforma Trabalhista (BRASIL 2017a) e a Lei da Terceirização (BRASIL, 2017b) vieram concretizar o aprofundamento da exploração do trabalho por meio da flexibilização das formas de contratação. Essas alterações, no campo jurídico-formal, realizam a regulamentação do trabalho temporário, autônomo e terceirizado, e da jornada parcial, além da criação de uma nova forma de contrato, a do trabalho intermitente e, por fim, adéquam a legislação às exigências impostas pelo capital na atualidade. As novas diretrizes do capital para o gerenciamento da classe trabalhadora não deixam de fora os professores da educação pública. Segundo a UNESCO (1998 apud SHIROMA; EVANGELISTA, 2011, p. 135), “[...] os 57 milhões de professores empregados nos sistemas de educação formal do mundo constituem a maior e mais específica categoria de pessoas envolvidas em ocupações de caráter profissional e técnico". No Brasil, os docentes compõem uma das maiores categorias de servidores públicos, conforme dados do Instituto de Pesquisa Econômica Aplicada (IPEA):

Em 2016, no nível municipal, do total de aproximadamente 6,3 milhões de vínculos, 1,7 milhões era constituída somente de professores, $27 \%$ do total de ocupados. Ao longo da série de 2003 a 2016, os valores se mantiveram próximos a esse patamar". [...] 0 cenário é similar no setor público estadual. Professores - incluindo pedagogos - respondem por $30 \%$ do total das ocupações no setor público - o percentual diminuiu de 32\% para 30\%, em 2016. [...] No âmbito federal, somente os professores respondem por $13 \%$ do total de ocupados do executivo - incluídos o total de civis e militares. O valor se ampliou, pois em 2003 correspondia a 9\%. Em termos absolutos, o total passou de 45 mil para 137 mil profissionais. Nota-se, portanto, que o total de professores triplicou neste período, no nível federal. (IPEA, 2016, p.02, grifo nosso)

Fica evidente que a categoria docente compõe a grande massa de trabalhadores e, portanto, é público-alvo das políticas que buscam adequar as relações trabalhistas às novas demandas do capital. Tendo isso em vista, procuramos compreender as características específicas das relações de trabalho desses profissionais, localizando o trabalhador docente no tempo presente, identificando as determinações e contradições que o constituem diante do padrão atual de acumulação. 
Para Marx,

Se nos for permitido escolher um exemplo fora da esfera da produção material, diremos que um mestre-escola é um trabalhador produtivo se não se limita a trabalhar a cabeça das crianças, mas exige trabalho de si mesmo até o esgotamento, a fim de enriquecer o patrão. Que este último tenha investido seu capital numa fábrica de ensino, em vez de numa fábrica de salsichas, é algo que não altera em nada a relação. Assim, o conceito de trabalhador produtivo não implica de modo nenhum apenas uma relação entre atividade e efeito útil, entre trabalhador e produto do trabalho, mas também uma relação de produção especificamente social, surgida historicamente e que cola no trabalhador o rótulo de meio direto de valorização do capital. Ser trabalhador produtivo não é, portanto, uma sorte, mas um azar. (MARX, 2008, p. 382)

Do exposto, destacamos dois aspectos importantes sobre trabalho produtivo: 1) constitui-se de produtor de mais-valor; 2) não importa qual o tipo de mercadoria produz, o que interessa é a relação de produção, não havendo diferença entre uma fábrica de ensino ou de salsichas. Embasados nessa concepção, Tumolo e Fontana (2008) afirmam que o fato de os professores serem, atualmente, em sua maioria, trabalhadores assalariados, não significa que eles são produtores de capital. Mesmo considerando que todos produzem valor de uso - o ensino -, e que atuam sob a lógica do capital, o que vai definir se o professor é ou não produtor de mais-valor é sua participação na relação de produção que produza mais-valor.

Com esse entendimento, para trazermos à baila as especificidades do trabalhador docente, apoiamo-nos em A. Silva (2018), que realizou importante estudo nacional sobre as dimensões da precarização do trabalho docente no século XXI. Em sua tese, a pesquisadora indica três movimentos em relação à precarização dos docentes das redes públicas de educação básica (estaduais e municipais): 1) o impacto das condições contratuais de trabalho por tempo determinado, sem plenos direitos, assim como as tendências de terceirização, pejotização e uberização surgidas nos anos de 2016 e 2017; 2) a precarização que atinge o trabalhador docente concursado, advinda da extensão e intensificação da jornada de trabalho, assim como da ausência de vínculos institucionais que geram uma lotação flexível e uma constante instabilidade; 3) a formação de uma camada de professores que atua em programas privatistas empresariais buscando melhores condições de trabalho e remuneração. Nessa lógica, Martins et al chamam a 
atenção para as empresas sociais de ensino ${ }^{1}$ no processo de ampliação das parcerias público-privadas na educação, que tiveram grande crescimento a partir dos anos 2000:

[...] é possível que a privatização de novo tipo avance através da contratação da força de trabalho docente [...]. Esses mecanismos podem significar o aprofundamento do controle do trabalho docente de tal modo a descaracterizar sua natureza e especificidade, produzindo fortes impactos na formação humana. (MARTINS et al., 2019, p. 65)

Esses dispositivos legais, associados a outras leis, criaram as bases para que o processo de privatização da educação pública, especialmente a educação infantil, se efetivasse no âmbito dos municípios brasileiros. Somando-se ao exposto, apresentaremos de forma exploratória algumas das relações entre o público e o privado na rede pública de educação de Florianópolis-SC.

\section{A punção do fundo público na Secretaria Municipal de Educação de Florianópolis}

Em Florianópolis, um marco da precarização das relações de trabalho no serviço público se deu no governo de Ângela Amin (PPB, hoje PP, 1997-2005), que, a partir de 1998, implementou uma reforma administrativa na prefeitura por meio da contratação de uma empresa privada de consultoria. Essa se responsabilizou por elaborar e executar a reforma administrativa de cunho gerencialista, visando o "[...] aperfeiçoamento dos métodos e processos de gestão, no sentido de implantar a eleição e perseguição de resultados, na medida do possível, expressos por índices e indicadores objetivos." (CARDOSO, 2008, p. 51). A reforma veio acompanhada de uma série de terceirizações, que abrangeram "[...] desde a coleta de lixo, setores específicos das secretarias como partes administrativas e centros de processamento de dados e a vigilância de dezenas de

\footnotetext{
1 Segundo os autores, "As 'empresas sociais de ensino' apresentam as seguintes características: a) não visam lucro como as empresas tradicionais, o que não significa que seus dirigentes não obtenham vantagens financeiras; b) desenvolvem atividades com financiamento público, complementadas ou não por meio de doações privadas; c) suas ações são focalizadas nas frações da classe trabalhadora que vivem os efeitos da exploração e da desigualdade socioeconômica de forma mais intensa por conta da precarização das relações de trabalho e da ausência de políticas sociais universais e de qualidade; d) podem ter vínculos com entidades religiosas ou não; e) não se confundem com movimentos sociais que reivindicam direitos sociais ou direitos civis; ) se apresentam para a sociedade e para o bloco no poder como promotoras do bem-comum." (MARTINS et al, 2019, p. 22).
} 
locais de trabalho." (SILVA, M., 2004, p. 51). Na educação implementou-se a terceirização dos serviços de merendeira, auxiliar de serviços gerais e vigias (SILVA, M., 2004).

Cardoso (2008) destaca alguns dos princípios do gerencialismo que foram adotados pela PMF: modernização da gestão, sistemas flexíveis e abertos, agilidade nas respostas, participação da comunidade, parcerias com a iniciativa privada, articulação intersetorial e ênfase nos resultados. Na Secretaria Municipal de Educação, e consequentemente nas escolas, surgem conceitos como: novo modelo de gestão, autonomia, gestão escolar, eficiência, eficácia, descentralização, accountability.

A eleição e reeleição do prefeito Dário Berger (PSDB², 2005-2012), que se deu em meio à acusação de fornecimento de licenças ambientais ilegais (PEREIRA; MELO, 2015), garantiu a continuidade das políticas de terceirização da força de trabalho e levou à Secretaria Municipal de Educação o professor Rodolfo Pinto da Luz ${ }^{3}$, que dirigiu a pasta durante todo o período. O secretário foi o principal responsável pela articulação do acordo entre a Prefeitura Municipal de Florianópolis e o Banco Interamericano de Desenvolvimento (BID), que resultou no contrato de empréstimo de mais de 59 milhões de dólares para financiar o Projeto de Expansão e Melhoria da Qualidade da Educação Infantil e do Ensino Fundamental de Florianópolis (MELGAREJO, 2017). Nas eleições de 2012, o então secretário, filiado ao PSD, concorreu à vaga de vice-prefeito na chapa de Gean Loureiro, que foi derrotada por César Souza Jr. Esse o reconvocou para o cargo de secretário, o que lhe garantiu a continuidade à frente das negociações com o BID, que foram concretizadas apenas em 2014.

\footnotetext{
${ }^{2}$ Antes de ser prefeito de Florianópolis, Dário iniciou sua carreira política como vereador na cidade vizinha, São José, pelo partido PL, em 1992. Em 1996, foi eleito prefeito da mesma cidade, pelo PFL, sendo reeleito no ano 2000. Em 2004, elegeu-se prefeito da capital pelo PSDB, sendo reeleito pelo PMDB, hoje MDB. Atualmente, ocupa o cargo de senador da República.

${ }^{3}$ Aposentado como procurador federal pela Universidade Federal de Santa Catarina (UFSC) (PORTAL DA TRANSPARÊNCIA, 2020), Rodolfo é professor da mesma instituição desde 1973, apesar de no mesmo ano ter sido nomeado assessor no Departamento de Assuntos Universitários do Ministério da Educação e Cultura. Retornou à universidade em 1980 para assumir a Pró-Reitoria de Administração. Em 1984, foi nomeado reitor da UFSC, sendo eleito em 1996 e reeleito em 2000. Entre um período e outro, presidiu o Instituto de Planejamento Urbano de Florianópolis, foi superintendente da Fundação Cultural de Florianópolis Franklin Cascaes e ocupou outros cargos no Ministério da Educação. Após sua terceira gestão na UFSC, assumiu a Secretaria Municipal de Educação, onde ficou por 12 anos. Em 2018, disputou o cargo de deputado estadual pelo PSD, ocasião em que recebeu $0,33 \%$ dos votos, quantia insuficiente para se eleger.
} 


\subsection{O acordo PMF-BID: avanço do capital sobre a educação municipal}

O contrato de empréstimo com o BID impulsionou as parcerias público-privadas e a materialização da educação pública como bem público não estatal, abrindo caminho para as empresas fornecerem desde a formação continuada, materiais didáticos, até a gestão escolar, transformando a escola em um celeiro das habilidades requeridas pelo mercado, inspiradas na teoria do capital humano - agora atualizadas com as necessidades da sociabilidade capitalista no século XXI, em especial as habilidades socioemocionais. Exemplo disso foi a contratação, em diferentes gestões, da empresa israelense Mind Lab, que se autoproclama "[...] pioneira no desenvolvimento de habilidades sociais, emocionais, cognitivas e éticas de forma integrada" (MINDLAB, 2020). A empresa havia firmado três contratos entre 2012 e 2015, totalizando R\$ 1.247.067,32. Após o acordo com o BID, os contratos “engordaram”, somando R\$1.889.696,334 em outros três contratos entre 2016 e 2019, um aumento de 66\% no valor dos contratos, de acordo com o levantamento realizado a partir do Portal da Transparência da PMF (FLORIANÓPOLIS, 2020).

A política de avaliação em larga escala municipal, denominada Prova Floripa, iniciada em 2007 e que até a edição de 2013 foi toda realizada com pessoal da própria SME, sendo que nos primeiros anos os próprios professores das unidades educativas elaboravam a avaliação e realizavam a correção (LIMA, 2018), também teve os contratos substancialmente elevados. Em 2011, a empresa Meritt Informação Educacional LTDA foi contratada para o processamento dos resultados da prova pelo valor de $\mathrm{R} \$ 94.274,35$ (FLORIANÓPOLIS, 2011), sendo que no ano seguinte o valor pulou para $\mathrm{R} \$ \mathbf{2 0 0 . 1 2 4 , 1 9}$ (FLORIANÓPOLIS, 2012). Em 2013, a empresa vencedora do pregão para contratação de empresa especializada para prestação de serviços de coleta, tratamento e organização dos dados foi a Foco Opinião e Mercado LTDA EPP, por R\$130.478,65 (FLORIANÓPOLIS, 2013). Após o acordo com o BID, a SME terceirizou todo o processo ao contratar o Centro de Avaliação Educacional da Universidade Federal de Juiz de Fora (CAEd/UFJF) para realizar a elaboração, aplicação, processamento, análise e devolutivas da Prova Floripa, de 2014 a 2018, pelo valor de R\$ 4.316.804,825. Até então, o CAEd era visto como “[...]

\footnotetext{
4 Valores corrigidos para dezembro de 2019 pelo IPCA-E.

${ }^{5}$ Valores corrigidos pelo IPCA-E para dezembro de 2019.
} 
uma instituição com fins privados que atua no setor público e pertencente a uma universidade pública." (LIMA, 2018, p. 81). Em pesquisa recente, Santos esclarece:

Cabe ressaltar que no ano de 2019 o CAEd passou a ser denominado Fundação CAEd, entidade privada sem fins lucrativos. A partir desta alteração na sua natureza jurídica, mesmo ainda anunciando o apoio à Universidade Federal de Juiz de Fora, a Fundação CAEd passa a ganhar maior autonomia administrativa e financeira, uma vez que deixa de funcionar junto à Fundação de Apoio e Desenvolvimento ao Ensino, Pesquisa e Extensão credenciada à UFJF e passa, ela própria, a se constituir como fundação credenciada ao MEC e ao Ministério de Ciência, Tecnologia, Informação e Comunicação. (SANTOS, 2019, p. 284)

Segundo Santos (2019), a Prova Floripa deixou de ser aplicada no ano de 2017 com a mudança na gestão municipal e a saída de Rodolfo Joaquim Pinto da Luz do cargo de secretário municipal de educação. Lima (2018) alerta que a participação estudantil na avaliação, que nos últimos anos passava dos $80 \%$, caiu para $42,6 \%$ na sua última edição, em 2016. A queda se deu devido ao posicionamento tirado pelos trabalhadores da RME de boicotar a Prova Floripa, em assembleia do SINTRASEM no dia 19 de outubro de 2016 (LIMA, 2018).

Outra política que contou com a resistência dos trabalhadores (SINTRASEM, 2015) foi referente à avaliação da educação infantil. O contrato com o BID foi firmado com uma cláusula especial que condicionava os repasses à contratação sem licitação da Fundação Carlos Chagas (MELGAREJO, 2017), o que se concretizou em março de 2015, quando a fundação privada foi contratada por R\$2.228.414,91 (FLORIANÓPOLIS, 2015). Em agosto de 2015, a instituição privada Universidade do Sul de Santa Catarina (UNISUL) foi contratada a partir de Seleção Baseada na Qualidade e Custo por R\$ 482.094,76 6 para a elaboração da matriz curricular do ensino fundamental e educação de jovens e adultos.

Em 2016, a empresa Planeta Educação Gráfica e Editora LTDA, que compõe o Grupo Vitae Brasil (SANTOS, 2019), foi contratada para atuar na formação dos candidatos à direção das unidades escolares no ano de 2016 pela SME por $\mathrm{R} \$ 375 \cdot 656,94$. No mesmo ano, a joint venture ModernaAvalia, composta por Editora Moderna Ltda. e Avalia Qualidade Educacional Ltda. (SANTOS, 2019) foi contratada para o fornecimento de uma

\footnotetext{
${ }^{6}$ Valores corrigidos para dezembro de 2019 pelo IPCA-E.
} 
plataforma digital de conteúdos para os componentes curriculares de língua portuguesa, matemática, ciências e inglês, para estudantes do $6^{\circ}$ ao $9^{\circ}$ ano do ensino fundamental por $R \$ 2.892 .795,52^{7}$.

\subsection{Terceirização da força de trabalho: negócio milionário}

A seguir, apresentaremos os principais contratos de terceirização de força de trabalho identificados a partir de um levantamento das informações sobre contratos da Secretaria Municipal de Educação da Prefeitura Municipal de Florianópolis, disponibilizados pelo Portal da Transparência do site e-gov ${ }^{8}$. Podemos perceber no gráfico 1 a seguir que os gastos com a terceirização de trabalhadores aumentaram constantemente na série histórica de 2002 a 2018, com exceção de 2006 e 2014, em que apresentou queda:

Gráfico 1 - Gastos da SME/PMF na rubrica "locação de mão de obra" (2002-2018)

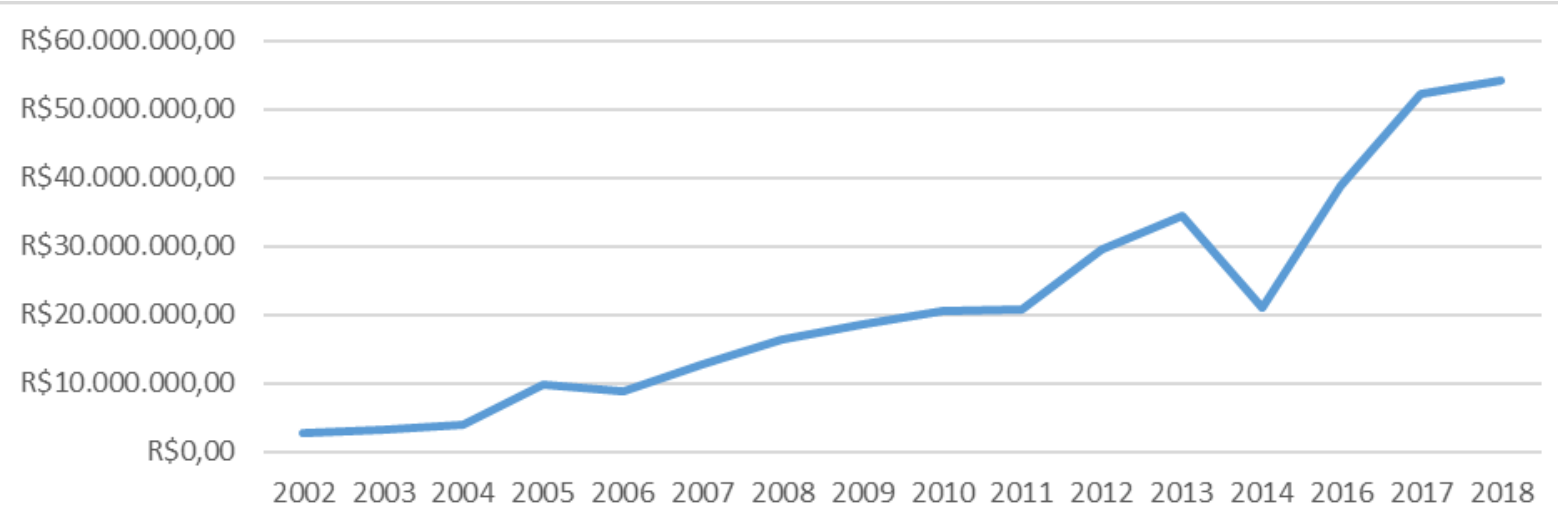

Dados: Elaborado pelos autores, 2020 com base nos dados do Portal e-gov. Valores corrigidos pelo IPCA-E. Nota: dados de 2015 não disponíveis.

A empresa Sepat Multi Service LTDA, fornecedora de nutricionistas terceirizadas, somou contratos ao custo de $\mathrm{R} \$$ 53.991.229,75, sendo 99\% para atendimento dos estabelecimentos de ensino. Entre setembro de 2017 e agosto de 2019, a empresa especializada em terceirizar força de trabalho, Orbenk Administração e serviços LTDA, assinou $\mathrm{R} \$$ 14.507.701,29 em contratos com a PMF para a área de limpeza, capina,

\footnotetext{
7 Valores corrigidos pelo IPCA-E para dezembro de 2019.

${ }^{8}$ Os dados podem ser acessados em: <https://e-gov.betha.com.br/transparencia/01037-031/main.faces>.
} 
pequenas podas e lavagem de roupas, sendo que desses, $\mathrm{R} \$$ 9.994.352,52 foram para atender os estabelecimentos de ensino (FLORIANÓPOLIS, 2020).

A empresa Orcali Serviços de Segurança LTDA possui contratos com a prefeitura desde 2005, que somam mais de 15 milhões de reais em valores não corrigidos. Somente para a pasta da educação, a empresa assinou contratos de $\mathrm{R} \$$ 9.997.185,93 em $2011^{9}$ (FLORIANÓPOLIS, 2020).

César Sousa Jr. (PSD, 2013-2016) venceu as eleições de 2012 com o auxílio da Khronos Segurança Privada LTDA, que abasteceu sua campanha com R\$250.000,00 via comitê municipal do PSD (BRASIL, 2020). Durante sua gestão, a empresa assinou sete contratos que totalizaram $\mathrm{R} \$ 15.281 .345,68$, em serviços terceirizados de segurança (FLORIANÓPOLIS, 2020).

No levantamento que fizemos a partir dos dados do Portal da Transparência (FLORIANÓPOLIS, 2020), na gestão de Gean Loureiro (DEM, 2017-2020) foram assinados 28 contratos a partir da verba do empréstimo com o BID, que somam R\$7.981.459,76, sendo que desses, $\mathrm{R} \$$ 3.886.207,06 foram para consultorias. A empresa Faz Educação e Tecnologia EIRELI recebeu, entre 2018 e 2019, $R \$ 2.298 .730,46$ para o fornecimento de formação continuada para os professores da rede municipal de educação e para a organização de eventos.

A terceirização da força de trabalho pela prefeitura revela-se como um mercado milionário, que abrange desde atividades como a lavagem de roupas das unidades escolares até a formação continuada de professores. Ao longo das últimas gestões uma gama ainda maior de postos de trabalho ligados à Secretaria Municipal de Educação foi terceirizada, conforme pode ser observado no Grafico 2

9 Valores corrigidos para dezembro de 2019 pelo IGP-M. 
Gráfico 2 - Percentual das despesas com locação de mão de obra e subvenções sociais em relação ao total da SME/PMF

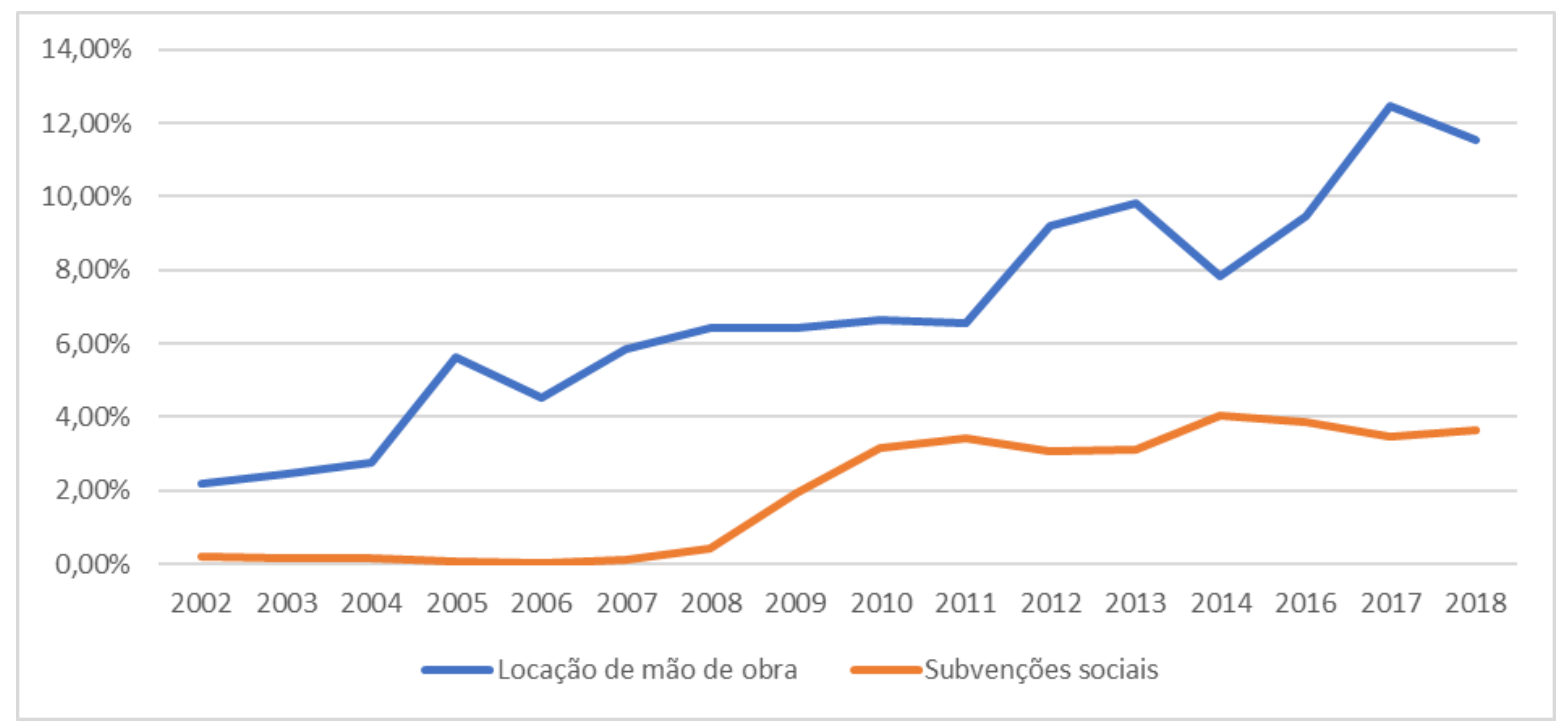

Dados: Elaborado pelos autores, 2020 com base nos dados do Portal e-gov.

Nota: Dados de 2015 não disponíveis.

Os dados disponíveis de 2002 a 2018 no banco de dados do Portal da Transparência (FLORIANÓPOLIS, 2020) permitiram constatar que a folha salarial ${ }^{10}$ representava 77,58\% dos gastos da pasta em 2002, sendo que em 2018 esse valor caiu para $54,33 \%$, enquanto os gastos com subvenções sociais ${ }^{11}$ e com locação de mão de obra cresceram de $0,19 \%$ e $2,20 \%$ para $3,63 \%$ e $11,54 \%$, respectivamente ${ }^{12}$. Os contratos para locação de mão de obra ultrapassaram a casa dos 50 milhões de reais em 2017 e 2018, enquanto as subvenções sociais somaram mais de 14 e 17 milhões de reais, respectivamente.

\footnotetext{
${ }^{10}$ Soma dos pagamentos da SME/PMF nos elementos "04 - contratação por tempo determinado" e "11 vencimentos e vantagens fixas" de acordo com o Portal da Transparência e-gov, com valores corrigidos para dezembro de 2019 pelo IPCA-E.

${ }^{11}$ O repasse de recursos da prefeitura para entidades que prestam serviços essenciais de assistência social, médica, cultural e educacional são registrados na rubrica de subvenções sociais.

${ }^{12}$ Valores corrigidos para dezembro de 2019 pelo IPCA-E.
} 


\subsection{0 crescimento das subvenções sociais}

Em um levantamento a partir dos gastos da Secretaria Municipal de Educação desde 2002, ano em que estão disponíveis os primeiros dados no Sistema de Fiscalização Integrada e Gestão (e-Sfinge), gerido pelo Tribunal de Contas do Estado de Santa Catarina $^{13}$ (TCE-SC), constatamos que até 2008 as subvenções eram destinadas principalmente às associações de pais e professores das escolas municipais. A partir de 2009 há um salto nos gastos com a rubrica, quando outras entidades privadas - em parte ligadas a igrejas ${ }^{14}$ - passam a receber subvenções mediante o conveniamento com a PMF para fornecer atendimento na educação infantil.

Nos primeiros dias após assumir a prefeitura, Gean Loureiro apresentou de uma só vez 36 projetos de lei para a câmara de vereadores, apelidados pelos municipários da cidade como "pacote de maldades", uma vez que diversas proposições atacavam frontalmente os direitos dos trabalhadores. A categoria entrou em greve, que se arrastou por 38 dias e findou após a retirada de grande parte dos ataques aos trabalhadores, o que não impediu a aprovação do Decreto $\mathrm{n}^{\circ}$ 17.361, de 15 de março 2017, que “[...] regulamenta as parcerias entre o município de Florianópolis e as Organizações da Sociedade Civil, para a consecução de finalidades de interesse público e recíproco, mediante a execução de projetos e atividades previamente estabelecidos em planos de trabalho." (FLORIANÓPOLIS, 2017, p. 01). No decreto fica estabelecido que os repasses por subvenções sociais devem ser "[...] destinados a atender despesas com ações a serem desenvolvidas por instituições privadas de caráter social, assistencial ou educacional, sem fins econômicos." (FLORIANÓPOLIS, 2017, p. 01).

As subvenções sociais para entidades conveniadas vêm crescendo constantemente na gestão de Loureiro. Ao final de 2017, houve repasses na ordem de $\mathrm{R} \$$ 15.545.567,17. No ano seguinte foram repassados $\mathrm{R} \$ 17.411 .238,78$, acréscimo de $12 \%$. Em

\footnotetext{
13 O sistema pode ser acessado em: <http://esfingeweb.tce.sc.gov.br:8080/LoginApp/SubmitLogon.do? event $=$ consultaAberta\&idEnte $=5>$.

${ }^{14}$ De acordo com dados coletados no sistema do TCE-SC (SANTA CATARINA, 2020), a associação privada Irmandade do Divino Espírito Santo (IDES), ligada à igreja católica, por exemplo, obteve R\$ 4.950.533,78 em subvenções somente nos três primeiros anos do governo de Loureiro. No mesmo período, a Sociedade Espírita de Recuperação, Trabalho e Educação (SERTE) recebeu R\$ 3.479.200,30. Ambas recebem subvenções sociais da Secretaria Municipal de Educação desde 2009. Os valores foram corrigidos pelo IGPM.
} 
2019, tivemos um aumento ainda maior, de 14\%, chegando a $\mathrm{R} \$ 19.925 .751,70$, em parte pela contratação da Associação de Saúde São Bento (ASB), que discorreremos a seguir.

O repasse para a ASB, de $\mathrm{R} \$ 2.161 .456,47$, foi a maior e mais polêmica subvenção social dos últimos anos, uma vez que a contratação da associação privada se deu envolta em um escândalo de possíveis documentos falsos (SINTRASEM, 2019) para atestar a experiência prévia na área exigida por lei. As denúncias são gravíssimas: o presidente da ASB é um dos investigados pelo Ministério Público do Rio Grande do Sul ${ }^{15}$, que apura o desvio de 24 milhões advindos de contratos com o governo do RS e com o Instituto de Saúde e Educação Vida, na área da saúde. Segundo a investigação, o dinheiro foi transferido justamente para a conta da ASB, que serviu de 'laranja' para o desvio de dinheiro público (COSTA, 2019).

O maior volume de dinheiro à entidade, em relação aos demais contratos com a PMF, deve-se a um novo padrão estabelecido pela prefeitura, que permite a contratação de profissionais para as atividades-fim e até mesmo a terceirização da força de trabalho de pessoa física e/ou pessoa jurídica sob responsabilidade da entidade conveniada, assim como todos os encargos trabalhistas, conforme o termo de colaboração firmado com a prefeitura (FLORIANÓPOLIS, 2019a). Logo nos primeiros meses de funcionamento das creches geridas pela associação privada, o sindicato denunciou:

O resultado já pode ser sentido pelas famílias que utilizam as creches, que tem denunciado o improviso e a falta de experiência na educação: falta de material pedagógico, falta de profissionais para atender as crianças, falta de segurança e até alimentos insuficientes. Já os profissionais da educação, que foram contratados sem nenhum tipo de concurso público, recebem salários muito abaixo do piso da categoria e tem sofrido com a falta de condições de trabalho recorrentes de todas estas irregularidades. (SINTRASEM, 2019, documento online)

Além de um descaso enorme com as famílias, o que gerou mobilização, atos, reuniões - e culminou em uma denúncia pública -, nas quais relatavam diversas irregularidades no atendimento:

\footnotetext{
${ }^{15} \mathrm{O}$ inquérito civil por improbidade administrativa, de $n^{\circ}$ 00757.000.192/2019, publicado no Diário Eletrônico do Ministério Público do Rio Grande do Sul, em 15 de agosto de 2019, tramita em sigilo na categoria "reservado" e tem entre os investigados Reni dos Santos, presidente da ASB.
} 
[...] falta constante de professores e auxiliares onde não há cobertura de um volante, inexperiência clara dos profissionais desde a diretoria ao corpo docente em sala, deixando somente 1 funcionário sozinho com 15 crianças durante todo o turno escolar, inexistência de projeto político pedagógico, falta de planejamento e controle dos professores, falta de HABITE-SE, falta de titulação dos atuantes, relatos de agressão física e verbal de uma ex-auxiliar de sala [...], gritos constantes de alguns funcionários com as crianças, perigo nas escadarias onde um funcionário desce com várias crianças ao mesmo tempo, falta de comunicação via agenda da rotina diária (não há), refeitório não é adequado a estatura das crianças e nem dá autonomia para elas, uso de canecas de VIDRO para tomarem água, desordenação das atividades lúdicas, falta de atividades externas já que as crianças ficam atualmente confinadas dentro das salas na maior parte do tempo, falta de controle na entrada e saída da escola. (COLETIVO DE PAIS, 2019, p. 01)

Após pressão da comunidade e do SINTRASEM, com denúncias, panfletagens e protestos públicos, o secretário municipal de Transparência, Auditoria e Controle, Sandro José da Silva, atendendo a ofício da Secretaria Municipal de Educação, instaurou uma Comissão Especial, “[...] visando a apuração da veracidade em relação à documentação apresentada no Edital de Chamamento Público n. 002/19/SME pela Associação São Bento" (FLORIANÓPOLIS, 2019b, p. 03). O prazo para a conclusão dos trabalhos da comissão era de 60 dias a partir do dia 03 de dezembro, data de sua publicação, porém, foi prorrogado por mais 30 dias em janeiro de 2020.

Gráfico 3 - Percentual de crescimento acumulado de gastos da SME/PMF

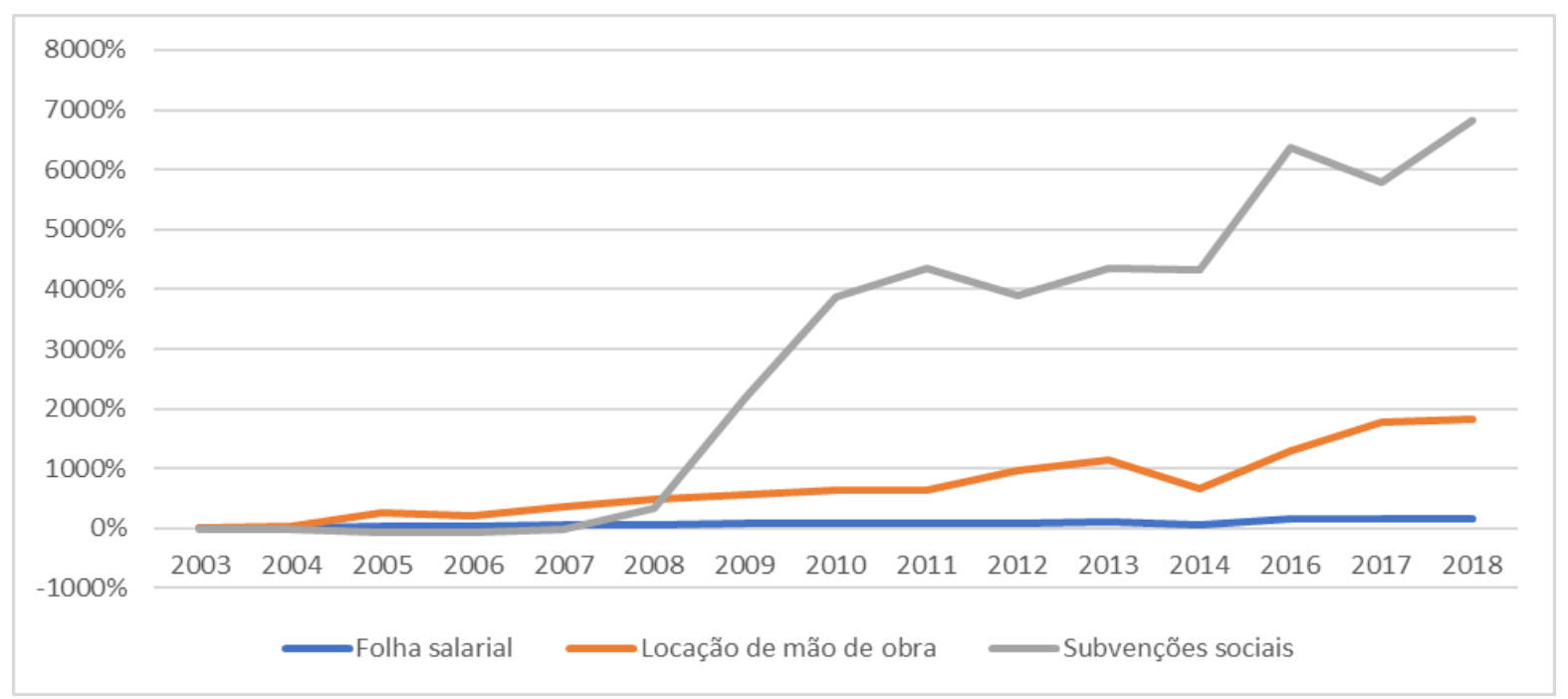

Dados: Elaborado pelos autores, 2020 com base nos dados do Portal da Transparência/e-gov. Valores corrigidos pelo IPCA-E para dezembro de 2019. Nota: Dados de 2015 não disponíveis. 
Em nosso levantamento, conforme o gráfico 3, constatamos que no período entre 2002 e 2018 o orçamento da SME cresceu 269\%, já a verba destinada pela Secretaria à locação de mão de obra cresceu 1837\%, enquanto para subvenções sociais o aumento acumulado foi de $6464 \%$. O crescimento da folha salarial, que representa historicamente o maior gasto da pasta, foi de apenas ${ }^{16} 158 \%$ no período ${ }^{17}$. A principal mudança na contratação da ASB, em relação às demais entidades conveniadas, foi a transferência da contratação de todo o pessoal para o atendimento às crianças das unidades de educação infantil. Essa tendência deve se agravar, uma vez que o projeto em curso da atual gestão municipal centra-se na transferência da gestão de novas unidades, notadamente da educação infantil, para Organizações Sociais (FLORIANÓPOLIS, 2018).

\section{Considerações finais}

A problemática que apresentamos de forma exploratória intenciona contribuir para a discussão sobre a escola em disputa e sobre o trabalhador professor. O elemento de terceirização da contratação de professores para escolas públicas, cujo vínculo de trabalho se estabelece com uma associação privada, coloca em questão a própria ideia de público e traz novos elementos de subsunção ao capital, pois, tende a transformar o trabalhador improdutivo (de mais-valor) em produtivo, permitindo que grupos empresariais, que inclusive migram de setores dentro do mercado, recuperem a taxa de lucro do capital, conforme a concepção marxista.

Assim, retomamos a dimensão quantitativa dos trabalhadores docentes, mostrando dados que apontam a educação escolar pública como um grande nicho de mercado, com determinadas "lacunas" a serem exploradas pela iniciativa privada. Encontramos evidências de que a tendência à terceirização da força de trabalho dos professores, como apontada por Martins et al (2019) e por A. Silva (2018), está em prática. É fundamental pontuar nesse processo de contratação, em que o Estado repassa o fundo público para a esfera privada, que a quase totalidade dos recursos que compõe o fundo público vêm da classe trabalhadora (SILVA, G., 2011). Assim, é a própria classe trabalhadora que está pagando indiretamente pelo ensino. Entendemos este momento

\footnotetext{
${ }^{16}$ Abaixo do IPCA-E no período, que foi de $169,67 \%$.

17 Valores corrigidos pelo IPCA-E para dezembro de 2019.
} 
como de transição, em que encontramos na escola pública trabalhadores docentes assalariados pelo Estado e, portanto, improdutivos - nos termos marxianos -, e trabalhadores docentes na condição de assalariados por empresas privadas ou empresas sociais de ensino, que poderiam ser configurados como participantes da relação direta de produção capitalista.

Destacamos a efetiva participação do Estado através da criação de leis e concessões que possibilitam essa expansão do capital sobre a educação pública, ao mesmo tempo em que reprime as manifestações contrárias e busca produzir consenso sobre o suposto mau uso do dinheiro público e a necessidade de o setor privado gerenciar esses serviços. A disputa da escola pública fica evidente no caso de Florianópolis, nas ações do sindicato para informar a comunidade acerca das denúncias que pairam sobre os conveniamentos, como o da ASB, com investigações e denúncias legais sobre o processo. Evidenciamos ainda a organização das famílias e a exigência da municipalização do NEIM (Núcleo de Educação Infantil Municipal). As contradições estão postas, assim como a luta de classes e os interesses por tudo isso que constitui a instituição escolar pública.

Os desdobramentos desse fenômeno que observamos em movimento, já indicado como tendência por outros pesquisadores, além da punção do fundo público pelo capital, da precarização do trabalho apontada pelo relatório que trata da Reforma Trabalhista, assim como pelos autores que discutem a piora programada das condições, qualificações e direitos do trabalho docente, confluindo com uma realidade mundial da classe trabalhadora, é ainda pouco estudado no campo das políticas educacionais. O que evidenciamos neste artigo é o movimento ferrenho de transformação do ensino, como direito formalmente universal, em mercadoria. 
BRASIL. Emenda constitucional $\mathbf{n}^{\circ}$ 95, de 15 de dezembro de 2016. Altera o Ato das Disposições Constitucionais Transitórias, para instituir o Novo Regime Fiscal, e dá outras providências. Brasília, DF: Presidência da República, 2016. Disponível em:

http://www.planalto.gov.br/ccivil_03/constituicao/Emendas/Emc/emc95.htm. Acesso em: 13 jun. 2018.

BRASIL. Lei n 13.467, de 13 de julho de 2017. Altera a Consolidação das Leis do Trabalho (CLT), aprovada pelo Decreto-Lei no 5.452, de 10 de maio de 1943, e as Leis nos 6.019, de 3 de janeiro de 1974, 8.036, de 11 de maio de 1990, e 8.212, de 24 de julho de 1991, a fim de adequar a legislação às novas relações de trabalho. Brasília, DF: Presidência da República, 2017a. Disponível em: < http://www.planalto.gov.br/ccivil_03/_Ato20152018/2017/Lei/L13467.htm>. Acesso em: 11 fev. 2019.

BRASIL. Lei $\mathbf{n}^{\circ}$ 13.429, de 31 de março de 2017. Altera dispositivos da Lei no 6.019, de 3 de janeiro de 1974, que dispõe sobre o trabalho temporário nas empresas urbanas e dá outras providências; e dispõe sobre as relações de trabalho na empresa de prestação de serviços a terceiros. Brasília, DF: Presidência da República, 2017b. Disponível em: http://www.planalto.gov.br/ccivil_03/_Ato2015-2018/2017/Lei/L13429.htm>. Acesso em: 11 fev. 2019 .

BRASIL. Emenda constitucional $n^{\circ}$ 103, de 12 de novembro de 2019. Altera o sistema de previdência social e estabelece regras de transição e disposições transitórias. Brasília, DF: Presidência da República, 2019. Disponível em: http://www.planalto.gov.br/ccivil_03/ constituicao/emendas/emc/emc103.htm. Acesso em: 2 jan. 2020.

BRASIL. Tribunal Superior Eleitoral. Contas da campanha eleitoral: dados das prestações de contas entregues - eleições 2004. [Brasília, DF: O Tribunal], 2020. Disponível em: http://www.tse.jus.br/eleicoes/eleicoes-anteriores/eleicoes-2004/prestacao-decontas/contas-da-campanha-eleitoral-dados-das-prestacoes-de-contas-entregueseleicoes-2004. Acesso em: 20 jan. 2020.

CARDOSO, A. M. O ideário gerencial no trabalho do diretor escolar: concepções, contradições e resistência. 2008. 134f. Dissertação (Mestrado em Educação) Universidade Federal de Santa Catarina, Florianópolis, 2008.

\section{COLETIVO DE PAIS. Manifestação dos pais dos alunos do NEIM Anirson Antônio} das Chagas. [S.I.: s.n.], 2019. Mimeografado.

COSTA, Melissa. ISEV desviou R\$24 milhões do hospital de Dois Irmãos e de outras cidades. $O$ diário, [S.I.], 2019. Disponível em: https://odiario.net/por-municipio/doisirmaos/isev-desviou-r-24-milhoes-do-hospital-de-dois-irmaos-e-de-outras-cidades/. Acesso em: 20 jan. 2020.

FLORIANÓPOLIS. Extrato do contrato n 357/EDUC/2011. Contratada: MERITT INFORMAÇÃO EDUCACIONAL LTDA. Florianópolis, SC, 5 mai. 2011. Diário Oficial do 
Município, Florianópolis, p. 2-2, ed. 470, 2011. Disponível em: http://www.pmf.sc.gov.br/arquivos/diario/pdf/

05_05_2011_18.29.27.fgbbo5bf6cfbf8fe8b2223623d5458be.pdf. Acesso em: 30 jan. 2020.

FLORIANÓPOLIS. Extrato do contrato $n^{\circ} 745 / E D U C / 2012$. Contratada: MERITT INFORMAÇÃO EDUCACIONAL LTDA. Florianópolis, SC, 8 nov. 2012. Diário Oficial do

Município, Florianópolis, p. 5-5, ed. 844, 2012. Disponível em:

http://www.pmf.sc.gov.br/arquivos/diario/pdf/

08_11_2012_18.54.34.0c47455b123c772ed31b9dfd169547bd.pdf. Acesso em: 30 jan. 2020.

FLORIANÓPOLIS. Aviso de resultado de julgamento da proposta de preço - tomada de preço $n^{\circ}$. 719/SMA/DLC/2013. Florianópolis, SC, 29 nov. 2013. Diário Oficial do Município, Florianópolis, p. 3-3, ed. 1107, 2013. Disponível em:

http://www.pmf.sc.gov.br/arquivos/diario/pdf/13_01_2014_13.48.

42.b1e3aogca40726ec6621f2909b532126.pdf. Acesso em: 30 jan. 2020.

FLORIANÓPOLIS. Decreto $n^{\circ}$ 13.192, de 16 de junho de 2014. Regulamenta a concessão de auxílios, contribuições, subvenções sociais e convênios do município de Florianópolis e dá outras providências. Florianópolis, SC, 18 jun. 2014. Diário Oficial do Município, Florianópolis, p. 2-2, ed. 1238, 2014. Disponível em: http://www.pmf.sc.gov.br/arquivos/diario/pdf/05_05_2011_18.29.27. fgbbo5bf6cfbf8fe8b2223623d5458be.pdf. Acesso em: 30 jan. 2020.

FLORIANÓPOLIS. Extrato do contrato n 146/EDUC/BID/2015 - Contratada: Universidade Federal de Juiz de Fora. Diário Oficial do Município, Florianópolis, p. 6-7, ed. 1430, 2015. Disponível em:

http://www.pmf.sc.gov.br/arquivos/diario/pdf/01_04_2015_22.03.34.04ba6a570af3449dd2 fo7cfccea38a02.pdf. Acesso em: 30 jan. 2020.

FLORIANÓPOLIS. Decreto n. 17.361, de 15 de março 2017. Regulamenta as parcerias entre o município de Florianópolis e as Organizações da Sociedade Civil, para a consecução de finalidades de interesse público e recíproco, mediante a execução de projetos e atividades previamente estabelecidos em planos de trabalho, nos termos das leis federais n. 13.019, de 2014 e 13.204, de 2015 e do decreto federal n. 8726, de 2016. Diário Oficial do Município, Florianópolis, p. 1-14, ed. 1904, 2017. Disponível em:

http://www.pmf.sc.gov.br/arquivos/diario/pdf/

16_03_2017_20.08.20.b4874a66761c6fc2ef8654e7aadgcacc.pdf. Acesso em: 30 jan. 2020.

FLORIANÓPOLIS. Decreto n. 18.710, de 25 de junho de 2018. Regulamenta o "programa municipal creche e saúde" já no âmbito do município de Florianópolis, instituído pela lei $\mathrm{n}^{\circ}$ 10.372, de 2018, e dá outras providências. Florianópolis: Prefeitura Municipal, 2018.

Disponível em:

https://leismunicipais.com.br/a1/sc/f/florianopolis/decreto/2018/1871/18710/decreto-n-

18710-2018-regulamenta-o-programa-municipal-creche-e-saude-ja-no-ambito-do-municipiode-florianopolis-instituido-pela-lei-n-10372-de-2018-e-da-outras-providencias. Acesso em: 3 ago. 2018. 
FLORIANÓPOLIS. SECRETARIA MUNICIPAL DE EDUCAÇÃO. Edital de chamamento público $S M E / S C N^{\circ}$ - 001/2019. Recebimento de documentação/seleção de planos de trabalho de organizações da sociedade civil (OSC) para fins de parceria com a Secretaria Municipal de Educação de Florianópolis a partir de 2019 com o objetivo de atender crianças a partir de 04 (quatro) meses até 05 (cinco) anos e 11 (onze) meses na educação infantil. Florianópolis: Prefeitura Municipal, 2019a. Disponível em:

http://www.pmf.sc.gov.br/arquivos/arquivos/pdf/28_01_2019_11.58.55.8a25foeo3d4dcc 523504bb8ae8c99178.pdf. Acesso em: 21 jan. 2020.

FLORIANÓPOLIS. Portaria $n^{\circ}$ 148, de 2 de dezembro de 2019. Portaria N. 148/SMTAC/2019. Florianópolis, SC, 3 dez. 2019. Diário Oficial do Município, Florianópolis, p. 3-3, ed. 2579, 2019b. Disponível em:

http://www.pmf.sc.gov.br/arquivos/diario/pdf/03_12_2019_21.01.32.9c06096b595fc69ddo gf6agf436oefc7.pdf. Acesso em: 30 jan. 2020.

FLORIANÓPOLIS. PREFEITURA MUNICIPAL DE FLORIANÓPOLIS. Portal da Transparência. 2020. Florianópolis: Prefeitura Municipal, 2020. Disponível em: http://www.pmf.sc.gov.br/transparencia/index.php. Acesso em: 5 jan. 2020.

GRAMSCI, A. Maquiavel, a política e o Estado moderno. 7. ed. Rio de Janeiro: Civilização Brasileira, 1989.

GRANEMANN, S. Monetarización y financiarización de las políticas sociales: expresiones del neodesarrollismo? In: Mariano Féliz y Maria Orlanda Pinassi. (org.). La farsa neodesarrollista: y las alternativas populares en América Latina y el Caribe. 1. ed. Buenos Aires: Ediciones Herramienta, 2017. p. 233-243.

IASI, Mauro. A crise do capital: a era da hipocrisia deliberada. In: Política, Estado e Ideologia na trama conjuntural. São Paulo: IPC - Instituto Caio Prado Jr., 2017. p. 59-84.

IPEA. Atlas do Estado brasileiro. Ocupações no serviço público (1995-2016). [S.I.: IPEA], 2016. Disponível em: http://www.ipea.gov.br/atlasestado/arquivos/rmd/3262conjunto8.html. Acesso em: jul. 2019.

KAMARAD, Roberto. Mercado educacional segue no alvo dos investimentos. [S.I.], 2017. Disponível em: https://www.blbbrasil.com.br/blog/mercado-educacional-investimentos/. Acesso em: 03 jan. 2019.

LENIN, V. O Estado e a revolução. Tradução: Aristides Lobo. São Paulo: HUCITEC, 1986.

LIMA, T. S.V. de. As implicações da Prova Floripa no trabalho docente. 2018. Dissertação (Mestrado em Educação) - Centro de Ciências da Educação, Universidade Federal de Santa Catarina, Florianópolis, 2018.

MARTINS et al. As parcerias público-privada na educação básica: uma análise sobre a realidade de quatro municípios de Minas Gerais. Relatório de Pesquisa. Núcleo de 
Estudos sobre Trabalho, educação e Política Educacional, Universidade Federal de Juiz de Fora, 2019.

MARX, Karl. Parte terceira. Lei: Tendência a cair da taxa de lucro. In: Marx, Karl. O capital. Rio de Janeiro: Civilização Brasileira, 2008, p. 277-316. Livro 3. Volume 4.

MELGAREJO, M. M. A Agenda do Banco Interamericano de Desenvolvimento para a Educação: um estudo do acordo com a Rede Municipal de Educação de Florianópolis. 2017. Dissertação (Mestrado em Educação) - Universidade Federal de Santa Catarina, Centro de Ciências da Educação, Programa de Pós-Graduação em Educação, Florianópolis, Santa Catarina, 2017.

MÉSZÁROS, I. Das crises cíclicas à crise estrutural. In: A atualidade histórica da ofensiva socialista. São Paulo: Boitempo, 2010. p. 69-98.

MINDLAB. Sobre a Mind Lab. [S.I.], 2020. Disponível em: http://mindlab.net/. Acesso em: 04 jan. 2020.

NETTO, José Paulo. Uma face contemporânea da barbárie. 2013. Revista Novos Rumos, Marília, v.50, n. 1, 2013. Disponível em: http://www2.marilia.unesp.br/revistas/index.php/ novosrumos/article/view/3436. Acesso em: 5 out. 2019.

OLIVEIRA, R. L. P. A transformação da educação em mercadoria no Brasil. Educação e Sociedade, Campinas, v. 30, n. 108, p. 739-760, out. 2009. Disponível em:

http://www.cedes.unicamp.br. Acesso em: 20 jul. 2017.

PEREIRA, Carlos; MELO, Marcus André. Reelecting Corrupt Incumbents in Exchange for Public Goods: rouba mas faz in Brazil. Latin American Research Review, Pittsburgh, v. 50, n. 4, p. 88115, 2015. Project Muse. http://dx.doi.org/10.1353/lar.2015.0054. Disponível em: https://www.jstor.org/stable/44000321. Acesso em: 15 jan. 2020.

PORTAL DA TRANSPARÊNCIA. Controladoria-geral da União. Servidor Público Federal: Rodolfo Joaquim Pinto da Luz. [Brasília, DF: O Portal], 2020. Disponível em:

http://www.portaltransparencia.gov.br/servidores/6810501. Acesso em: 20 jan. 2020.

SANTA CATARINA. TRIBUNAL DE CONTAS DO ESTADO. Sistema de Fiscalização Integrada de Gestão. [Florianópolis: TCE], 2020. Disponível em:

http://esfingeweb.tce.sc.gov.br:8080/LoginApp/

SubmitLogon.do?event=consultaAberta\&idEnte=5. Acesso em: 25 jan. 2020.

SANTOS, Márcia Luzia dos. Formação continuada na rede municipal de ensino de

Florianópolis: financeirização da educação básica e a (con)formação docente. 2019. 360

p. Tese (Doutorado em Educação) - Universidade do Estado de Santa Catarina, Centro de Ciências Humanas e da Educação, Programa de Pós-Graduação em Educação, Florianópolis, 2019.

SEKI, Allan Kenji. Financeirização do capital na educação superior: articulações entre a apropriação de parcelas do fundo público e a desregulamentação da educação nacional. 
In: COLÓQUIO INTERNACIONAL MARX E O MARXISMO 2017: de o capital à revolução de outubro (1867 - 1917). 2017, Niterói. Anais [...]. Niterói: [s.n.], 2017. Disponível em: http://www.niepmarx.blog.br/MM2017/anais2017/MC48/mc481.pdf. Acesso em: 14 dez. 2019.

SEKI, Allan Kenji. Kroton Educacional: em termos de educação pública nunca experimentamos um inimigo com uma força social tão concentrada como esse. [Entrevista cedida a] André Antunes. Portal EPSJV/Fiocruz, Rio de Janeiro, 27 de abril 2018. Disponível em: http://www.ihu.unisinos.br/578444-kroton-educacional-em-termosde-educacao-publica-nunca-experimentamos-um-inimigo-com-uma-forca-social-taoconcentrada-como-esse. Acesso em: 8 fev. 2019.

SHIROMA, E., O.; EVANGELISTA, O. Avaliação e responsabilização pelos resultados: atualizações nas formas de gestão dos professores. Perspectiva, Florianópolis, v.29, n.1, 127-160, jan./jun. 2011. Disponível em:

http://gepeto.ced.ufsc.br/files/2015/03/avaliacao1.pdf. Acesso em: 7 mar. 2018.

SILVA, M. F. Lutas e resistências dos servidores públicos contra a aplicação das políticas neoliberais na Prefeitura Municipal de Florianópolis entre 1997 e 2000. 2004. $156 f$. Dissertação (Mestrado em Educação e Cultura) - Universidade do Estado de Santa Catarina. Florianópolis, 2004.

SILVA, Amanda, M. Dimensões da precarização do trabalho docente no século XXI: o precariado professoral e o professorado estável-formal sob a lógica privatista empresarial nas redes públicas brasileiras. 2018. Tese (Doutorado em Educação) - Programa de PósGraduação em Educação da Faculdade de Educação da Universidade Federal do Rio de Janeiro, 2018.

SILVA, G, S. Fundo público e políticas sociais: o trabalho necessário sobre a égide do capital portador de juros. In: CIRCUITO DE DEBATES ACADÊMICOS, 1., 2011. Anais [...]. [S.I.]: Ipea, 2011. Disponível em:

http://www.ipea.gov.br/code2011/chamada2011/pdf/area2/area2-artigog. Acesso em: 8 jun. 2019.

SINTRASEM. Sobre a pesquisa "Avaliação da qualidade e elaboração do sistema de monitoramento da Educação Infantil da Rede Municipal de Florianópolis".

[Florianópolis], 2015. Disponível em: http://sintrasem.org.br/Default/Noticia/1132/sobre-apesquisa-\%E2\%80\%9Cavaliacao-da-qualidade-e-elaboracao-do-sistema-de-monitoramentoda-educacao-infantil-da-rede-municipal-de-florianopolis\%E2\%80\%9D. Acesso em: 20 jan. 2020.

SINTRASEM. Exclusivo: Gean entrega creches de Florianópolis para empresa laranja. Florianópolis, 2019. Disponível em: http://www.sintrasem.org.br/Default/Noticia/9848/exclusivo-gean-entrega-creches-deflorianopolis-para-empresa-laranja. Acesso em: 25 nov. 2019. 
SIMIONATTO, I. A trajetória intelectual de Gramsci. In: SIMIONATTO, I. Gramsci: sua teoria, incidência no Brasil, influência no serviço social. 4. ed. São Paulo: Cortez, 2011. p. 29- 92

TUMOLO, P, S; FONTANA, K, B. Trabalho docente e capitalismo: um estudo crítico da produção acadêmica da década de 1990. Educ. Soc., Campinas, v. 29, n. 102, p. 159-180, abr. 2008. Disponível em:

<http://www.scielo.br/scielo.php?script=sci_arttext\&pid=S010173302008000100009\&Ing= pt\&nrm=iso>. acessos em: 28 jul. 2020.

<http://dx.doi.org/10.1590/S010173302008000100009>.

Universidade do Estado de Santa Catarina - UDESC Programa de Pós-Graduação em Educação - PPGE

Revista Linhas

Volume 21 - Número 46 - Ano 2020

revistalinhas@gmail.com 